\title{
Climate projections and their impact on policy and practice
}

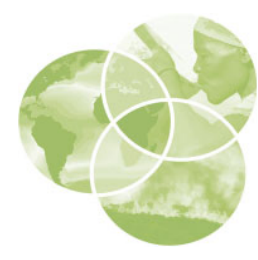

Maria Carmen Lemos ${ }^{1 *}$ and Richard B. Rood ${ }^{2}$

\begin{abstract}
This article examines the relationship between projections of climate change and the responses to those projections. First, it discusses uncertainty and its role in shaping not only the production of climate projections but also the use of these projections by decision makers. We find that uncertainty critically affects the way climate projections move from useful to usable, where usefulness is defined by scientists' perception of users' needs, and usability is defined by users' perception of what knowledge can be readily applied to their decision. From the point of view of the natural scientist, we pose that there is an uncertainty fallacy, that is, a belief that the systematic reduction of uncertainty in climate projections is required in order for the projections to be used by decision makers. Second, we explore the implications of climate projections for policy and decision making, using examples from the seasonal climate forecast applications literature as an analog. We examine constraints and opportunities for their application in policy and practice and find that over-reliance on science and technical solutions might crowd out the moral imperative to do what is needed to improve livelihoods and to guarantee ecosystems' long-term sustainability. We conclude that, in the context of high uncertainty, decision makers should not look for 'perfect' forecasts, but seek to implement knowledge systems that integrate climate projections with other kinds of knowledge and that consider the multiple stressors that shape their decision environment. ๑ 2010 John Wiley \& Sons, Ltd. WIREs Clim Change 20101 670-682
\end{abstract}

\section{INTRODUCTION}

$\mathrm{T}$ he Fourth Assessment Report of the Intergovernmental Panel on Climate Change (IPCCAR4) published in 2007 has labeled climate change 'unequivocal'. ${ }^{1}$ Yet, despite growing evidence that the climate is changing, there is still a significant uncertainty regarding how people, ecosystems, and structures will experience these changes. Part of the problem remains in the high level of uncertainty surrounding the projections of the changes in the physical climate of the Earth for the coming decades, including how much and how quickly the Earth will warm, sea level will rise, and the weather will change. This uncertainty varies both across scales (geographical and temporal) and across systems (human, environmental, and physical). Because the consequences of

\footnotetext{
*Correspondence to: lemos@umich.edu

${ }^{1}$ School of Natural Resources and Environment, University of Michigan, Ann Arbor, MI, USA

${ }^{2}$ Department of Atmospheric, Oceanic and Space Sciences, University of Michigan, Ann Arbor, MI, USA
}

DOI: $10.1002 /$ wcc. 71 these changes can be devastating to social, biological, and physical systems worldwide, there is great motivation on the part of decision makers, in both the public and private sectors, to acquire and understand information that can inform their decisions. Despite evidence that policy makers often act under great levels of uncertainty in many policy areas, ${ }^{2-4}$ there is relatively little empirical evidence of how they use climate predictions ${ }^{\mathrm{a}}$ and with what results. Although the focus on improving predictions and decreasing uncertainty has been a priority in research-funding programs, understanding whether this focus increases use by decision makers has received less attention. ${ }^{5}$

In the next sections of this article, we explore three themes frequently explored in the literature related to the use of climate projections in decision making:

1. Uncertainty in science is a product of the research process, and it makes decision making more complex. In response to users' perceived needs, scientists have focused on developing more powerful and scaled-down 
climate predictions; this drive to improve climate predictions has shaped both atmospheric and social scientists' research agendas.

2. Knowledge producers and users often perceive the usefulness of scientific knowledge differently, and these diverse perceptions may constrain the use of climate projections. Uncertainty and climate predictions' lack of skill have been frequently used to justify policy paralysis and inaction. One argument is that if preventive action involves steep costs (both financial and political), then policy makers are much more likely to resort to a wait-and-see position. Implicitly, in these cases, the level of uncertainty is too large in relation to what decision markers perceive they need. Other obstacles to practical use of predictions include institutional mismatch and constraints, competing issues, lack of resources, and faulty communication.

3. As prediction science matures and both scientists and decision makers become more aware of the constraints and possibilities to use climate projections, a new opportunity for framing their relationship emerges as they increasingly seek to interact with each other. This interaction happens, for example, in the context of scientific assessments or of policy implementation. In practice, this interaction may lead decision makers and scientists to integrate projections into broader decision environments that include not only climate but also other stressors affecting decision making.

Through the discussion of these themes, we explore the conditions that shape the ways decision makers use or fail to use climate projections. We then examine one area of climate-projection application, namely, the use of seasonal climate forecasts (SCFs).

\section{PROJECTIONS, PREDICTION, AND THE ROLE OF UNCERTAINTY}

In this section, we discuss the role and implications of uncertainty in the discovery and use of climaterelated knowledge. In scientific research, uncertainty is an intrinsic part of the process and a motivator of research. In fact, the investigation by scientists of different sources of uncertainty is an important focus of research. This scientific use of uncertainty as a research focus stands in contrast to uncertainty as source of complication for decision making. We briefly discuss the history and nature of climate projections in order to explore the role of uncertainty.
The history of climate change as a scientific problem is much older than its history as a social and public policy issue. For example, Weart ${ }^{6}$ points out that the basic projection that the Earth will warm in the presence of increasing greenhouse gases relies on physics that have been known for more than 200 years. Even before modern computationally based model predictions, global warming was being discussed by scientists such as Arrhenius, ${ }^{7}$ Callendar, ${ }^{8}$ and Budyko. ${ }^{9}$ The era of modern climate modeling can be traced to early models that were able to represent, explicitly, the transport of heat from equator to poles by the motions of the atmosphere and oceans. ${ }^{10}$ However, the response of the Earth's weather and climate to incremental warming by greenhouse gases is complicated by the presence of water as vapor, liquid, or ice, which contributes to a set of feedback processes that can either amplify or diminish the initial incremental warming. This complex response is in sharp contrast to the simple, underlying physics of greenhouse-gas warming and the difference in complexity has important implications for policy. It has been relatively easier for scientists to reach a consensus that climate is changing ${ }^{1}$ than it has been to inform decision makers about the specific character and magnitude of those changes.

The IPCC is the main organization responsible for the assessment and dissemination of climate projections based on the scientific literature published in refereed journals. In a recent review of its standards, Farber ${ }^{11}$ argues that the IPCC raises the credibility of the projections of climate change above the normal standards of scientific research, endowing them with enough certainty to have legal standing in the US judicial system-something economic models have failed to accomplish so far.

The IPCC-AR4 basic projections of climate change for the year 2100 are summarized as follows:

1. For the lowest projections of greenhouse-gas emissions considered, the global average of the temperature at the surface of the Earth in 2100 will increase between 1.1 and $2.9^{\circ} \mathrm{C}$, and the global mean sea level will increase between 0.18 and $0.38 \mathrm{~m}$.

2. For the highest emission scenario considered, the temperature will increase between 2.4 and $6.4^{\circ} \mathrm{C}$, and the global mean sea level will increase between 0.26 and $0.59 \mathrm{~m}$. Both ranges of sea level rise predictions, based on lower and higher emission scenarios, are qualified by the statement: 'excluding future dynamical changes in ice flow'. 
The uncertainty associated with these predictions has important implications for whether and how they are used in practice. On the one hand, for the scientist, reduction of uncertainty is often posed as a motivation for new scientific research. For the user, on the other hand, uncertainty may act as a constraint in the use of projections. Uncertainty is also difficult to define and its quantification difficult to calculate. In the short and deceptively straightforward summary above, there are already four different nuances of uncertainty.

First, the range of temperatures and sea level rise expresses uncertainties in the prediction of parameters intrinsic to the physical climate. These uncertainties can be quantified by comparison of model projections with observations. They may be directly related to details of the model construction, for example, the treatment of clouds and ice sheets. In predictionbased scientific investigation, the reduction of errors and, hence uncertainty, is an explicit goal. Second, the range of greenhouse-gas emissions expresses uncertainties in our knowledge of the amount of greenhouse gases that will be emitted due to human activity. These emissions depend on decisions that happen outside of the realm of physical science. Third, the qualification of the sea level rise projections by the statement 'excluding future dynamical changes in ice flow' expresses the fact that we know that there are processes in the climate models that are potentially important and poorly represented or not represented at all. Finally, Farber's ${ }^{11}$ argument discussed above represents a fourth evaluation of uncertainty, when he concludes that the IPCC process increases the certainty of climate projections because its completeness and openness reduces the possibility of fundamental flaws in the conclusions of global warming. This type of judgment by people outside the community of climate scientists is an important indicator of the robustness of knowledge. It addresses, with a documented method of evaluation, whether nonscientists who are users of the knowledge generated by the scientific investigation of the Earth's climate find the information convincing. These distinct nuances of uncertainty just begin to span the spectrum of uncertainty that both scientists and decision makers must face. This wider spectrum would include, for instance, the uneven and inconsistent expression of uncertainty by scientists. ${ }^{12}$

In the study of the Earth's weather and climate, predictions are often used to verify the quality of knowledge and inform the quantification of uncertainty of our understanding, for example, of the atmosphere. The classic problem is weather prediction, in which a deterministic forecast is made of a set of environmental parameters. Temperature, pressure, wind, and rain are predicted for a particular place and a particular time, and it is possible to verify these predictions with observations. There are uncertainties from a variety of sources in weather predictions, and these are communicated in, for example, probability of precipitation. Deterministic weather forecasts and simple statements of probability of precipitation are attractive to users because they can be easily translated into a decision. For example, depending on weather forecasts, users can postpone sporting events or anticipate mowing their lawns. There is, however, more information about uncertainty than what is expressed in the simple and direct expression of probability of precipitation. For example, there are uncertainties related to known model shortcomings and uncertainties related to errors in the observations that are used to initiate the forecast. Focusing on what is known about uncertainty, research strategies that take advantage of this information are possible. One example is the concept of probabilistic predictions where, rather than a single deterministic forecast, ensembles of forecasts are used. These forecasts are combined with the idea that, in the least, the random component of the uncertainty can be reduced. ${ }^{13}$ In this case, uncertainty becomes a source of scientific information that provides a mechanism for improving the forecast, and potentially, the usability of the forecast. By investigating and managing uncertainty, a better forecast is generated. On the basis of this scientific practice, scientists have been motivated to provide more detailed information on uncertainty to increase its use. ${ }^{14,15}$

These two types of forecasts, probabilistic and deterministic, provide brackets for the scientist, in that the deterministic forecast is a specific estimate of what will happen, and the probabilistic forecast is a range of what is expected to happen. Weather forecasts are often called predictions because of their deterministic nature. Estimates of how the climate will change are often labeled as projections or assessments, because deterministic forecasts of climate change are not formally possible. ${ }^{16}$ However, as discussions of climate change permeate society, discussions of uncertainty from a scientific perspective are lost and projection and prediction become synonymous in practice. ${ }^{12,17}$

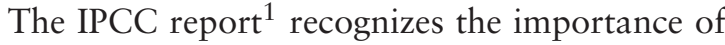
communicating uncertainty and discusses its findings in terms of confidence and likelihood. Confidence is defined with well-known expressions like very high to mean 9 out of 10 , medium 5 out of 10, etc. Something is likely to happen means that there is a $66 \%$ probability of occurrence. These statements of uncertainty strive to incorporate the different sources and types of uncertainty that are suggested in the example of the IPCC predictions given above. ${ }^{18}$ Overall, to 
assess uncertainty, scientists draw on 'the strength and consistency of the observed evidence, the range and consistency of model projections, the reliability of particular models as tested by various methods, and, most importantly, the body of work addressed in earlier synthesis and assessment reports'(Ref 19, p. 8). In terms of relative uncertainties, it is safe to say that those associated with the projections that the surface of the Earth will, on average, warm are smaller than the uncertainties related to knowledge of greenhouse-gas emissions and socioeconomic impacts. ${ }^{20}$ This is because climate models are based on physics, which (1) allows for the investigation of cause and effect, (2) supports predictions, and (3) can be verified with observations, whereas different emissions scenarios depend on contentious international agreements, national-scale policy implementation, and even social and behavioral norms at smaller scales. The uncertainty related to known inadequacies, such as those related to the treatment of ice sheets dynamics in models, indicates known risks. The role of processes that may be important to climate change and impacts but that have not yet been identified ('unknown unknowns') is expected to add yet another layer of uncertainty to projections.

Regarding IPCC projections, statements concerning average surface warming and sea level rise are the most robust. The consistency of these projections from one IPCC report to the next, on one hand, contributes to confidence that the physical processes in the models are reasonably represented. On the other hand, the fact that the range of the projections does not get smaller with successive reports frustrates the users of climate projections and the sponsors of climate research. Finally, as the spatial and temporal specificity of a projection increases, uncertainty also increases.

We are left, therefore, with daunting complexity in the quantification and specification of scientific uncertainty. We can conclude 'unequivocally' that the Earth's surface will warm due to increasing anthropogenic greenhouse gases. We can say, with similar confidence, that this may, for example, contribute to the melting of ice sheets, which, in turn, increases the risk of disruption to humans through rising sea level. Hence, we can assess the uncertainty well enough to know we need to reduce the emissions of greenhouse gases, that is, to motivate the development of mitigation policy. Yet, we still fall short from being able to inform policy makers of how high the sea walls should be in the coastal areas of South America or the shores of the Cayman Islands. ${ }^{21}$

In the next three sections, we examine the reasons behind the apparent disconnect between the expected potential value of climate predictions and the reality of inaction in preparing and offsetting impacts of climate change. We then explore the implications of this disconnect.

\section{USEFUL, USABLE, AND DESIRABLE}

We start by exploring the concepts of useful and usable and how they influence science, especially climate projection production and use. In an environment of high uncertainty and risk, inadequate or no information, and no or little previous experience, our ability to predict before we act can be very poor. ${ }^{2,4}$ Often in these cases, the alternative is to not do anything, at least until better information develops. Especially in the case of environmental policy making, where many of the outcomes are irreversible or very difficult to correct (e.g., species extinction, lake eutrophication), inaction can be costly. ${ }^{22}$

We pose that there are two factors that explain the disconnection between the perceived usefulness of climate predictions and their lack of use in decisionand policy making. First, different actors perceive the usefulness of scientific information differently. Scientists, for example, when choosing the focus of their research, may make an assumption of what they think decision makers need and hope their work will meet that need. Users, in turn, may define their need differently. However, scientists and users do not uniformly make the same assumption about what they think is useful and what they know is usable. Thus, some scientists' assumptions may be closer to users' definition of need, while others' may be farther away. In this sense, there is a range of perceptions of usefulness and usability. For example, within the Climate Assessment for the Southwest (CLIMAS) funded by the National Oceanic and Atmospheric Administration (NOAA), scientists focused first on the production of a regional climate forecast tool, which they perceived as meeting stakeholders' needs. However, subsequent interactions with potential users revealed that these decision makers wanted additional information, in particular a forecast-evaluation and decision-support tool. (Refs 23, p. 48, 24, p. 53). In northeast Brazil, for example, scientists from the state meteorological agency believed that the seasonal climate forecasts (SCFs) they produced would be useful to farmers making planting decisions. Agricultural policy makers, implementing a seed-distribution program, perceived SCFs as usable when they used the forecasts to issue a strict planting calendar to which farmers had to abide in order to have access to the government-distributed seed. Rain-fed farmers, in contrast, resented SCFs because they associated their use with a lack of access to seeds and as a constraint to their planting choices. 
In the farmers' view, seeds should be available at the beginning of the season irrespective of climate predictions and they should be the ones making the decision of when to plan, not the government. ${ }^{25}$ Here, perceptions of usefulness and usability varied across these different actors and were influenced by different factors and decision contexts.

While the differentiation between useful and usable has been characterized in the literature, ${ }^{26}$ these two concepts have often been used interchangeably. We suggest the difference between useful and usable is a material quality-to borrow from the language of marketing, usefulness is about functionality and desirability; usability is about application and fit, that is, what scientists ideally perceive as useful may not be applicable or fit decision-making processes and decision environments in practice. Although usefulness is a necessary condition, it is not sufficient to guarantee use. On the basis of empirical evidence from CLIMAS, Lemos and Morehouse (Ref 27, p. 62) define usable science as that which 'directly reflects expressed constituent needs, should be understandable to users, should be available at the times and places it is needed, and should be accessible through the media available to the user community'. For example, SCFs are, in principle, useful for farmers since knowing in advance how much it is likely to rain is a good thing in agriculture. However, for a subsistence rainfed farmer in Africa, with no options in terms of alternative technologies, it is not usable without ancillary policy interventions such as access to credit or to technological innovations. ${ }^{28}$ SCF forecasts, however, can be valuable to resource-rich irrigated farmers in Australia planning their investment for the following season. ${ }^{29}$

The second element of the disconnect between the perceived usefulness of climate predictions and their lack of use in decision making is that moving prediction science from useful to usable may depend on a suite of factors, institutions, and resources including (1) technical factors (e.g., information formatting, timing of release, level of skill); (2) cognitive factors that influence the way users perceive the sciencegenerated information (e.g., communication, trust, credibility, accessibility, experience); (3) institutions that facilitate or constrain the use of new knowledge; and (4) structural factors that shape the capacity of different decision makers to use projections (e.g., lack of access to knowledge, lack of choice in term of alternative technologies or policy change). ${ }^{23,24,27,30-35}$ Recent research suggests that the growing interaction between climate-projection producers and potential users can increase their rate of use by decision makers. ${ }^{27,36}$ In addition, the creation of boundary organizations that facilitate the exchange between knowledge producers and users can also increase the usability of climate projections. ${ }^{37}$ For example, organizations such as the United Kingdom's Climate Impacts Program (UKCIP) seek to play a pivotal role in facilitating the use of knowledge to inform climateadaptation action (for example, for numerous reports and technical papers, see http://www.ukcip.org.uk/).

In this section, we have argued that there is often a disconnection between what scientists perceive as useful and what decision makers think is usable. We have also reviewed a few of the conditions that move predictions across the range of usefulness. In the next section, we explore different models of science and policy interaction and lay the groundwork for exploring the implications of predictions' inherent uncertainty for decision making, especially in justifying inaction.

\section{SCIENCE-POLICY INTERACTIONS}

Weiss ${ }^{38}$ proposes two models for the use of scientific research in policy making: the decision- and the knowledge-driven models. In the decision-driven model, policy makers, when faced with a problem, either look for solutions in the pool of pre-existing research products or commission new research to meet their needs. In the former, existing research might be only marginally applicable to the problem and a certain adjustment is necessary in this model. In the second model, commissioned research is expected to have direct application in decision making. In both cases, science is expected to be readily applicable to problem solving. In the knowledge-driven model, such expectation is lower and research is in some cases 'used for policy making not so much because an issue requires elucidation but because research has uncovered an opportunity that can be capitalized upon' (Ref 38, p. 29). Here, the 'solution' emerges first and scientists look for a problem where it can be applied. Weiss argues that in these cases, the 'sheer existence of knowledge presses it toward development and use' (p. 30) rather than the other way around. One consequence is that the emerging solution may not always fit the problem policy makers want to solve. For example, although forecast producers have often expressed their belief that SCFs are useful for managing water resources, water managers often perceive them as too coarse (i.e., lacking in spatial and temporal precision) for the kind of decisions they make. ${ }^{31}$

Evidence from the empirical literature focusing on SCF use suggest that their production and use has been moving from knowledge- to decisiondriven approaches, as scientists go beyond the physics 
of prediction to engage on research and practice designed to understand what it takes to make predictions usable (see the following section for more detail). This effort has often been carried out by interdisciplinary teams of scientists (physical and social) working together with stakeholders in the context of integrated assessments and participatory models of science-policy interaction. ${ }^{27,33}$ As mentioned in the previous section, because of greater interaction between producers and users, the diversity of perceptions of what constitutes useful/usable knowledge may decrease as scientists and decision makers learn about each other's work. For example, users may learn of the difficulties and limitations scientists face regarding spatial downscaling of climate impacts projections, while scientists may develop a better understanding of how users' decision environments affect their ability to apply climate projections at several levels of uncertainty. ${ }^{27}$ Partly as a result of this interaction, both scientists and policy makers are increasingly aware that to solve the potential problems related to climate impacts, scientific priorities and practices need to change to include decision support, that is, 'organized efforts to produce, disseminate, and facilitate the use of data and information in order to improve the quality and efficacy of climate-related decisions'. In addition, there is growing realization that 'the information that is needed is not only about climate, but also about changes in social and economic conditions that interact with climate change and about the state of knowledge and uncertainty about these phenomena and interactions' (Ref 39, p. S1).

\section{CLIMATE PREDICTIONS AND IMPLICATIONS FOR SCIENCE AND POLICY}

As argued above, part of the difficulty of using climate projections in decision making can be traced to the definition and framing of climate change as a problem. When a problem exists first in the realm of science and is not readily experienced by the public, the way it gets inserted in the policy agenda may critically define the kind of action decision makers take to solve it. ${ }^{22}$ For example, it may be difficult to convince current generations to make sacrifices to save the world for future ones. $^{22}$ In this context, the decision to use highly uncertain scientific knowledge such as climate projections and SCFs in policy making can be haphazard, may backfire, and even lead to undesirable outcomes. On the one hand, application may lead to a period of 'new technology blues', ${ }^{40}$ that is, when the tribulations of implementing a new technology can result in its rejection, even before new and better applications can be uncovered. For example, in northeast Brazil farmers' perception that climate forecasts were 'wrong', despite the fact that probabilistic forecasts cannot be deterministically either right or wrong, contributed to the discrediting of not only the forecasts but also of the forecasters and the agency releasing them as well. ${ }^{40}$ On the other hand, undesirable outcomes motivate further adjustment to either get it right or discard it as a desirable solution. In the best-case scenario, when this process is carefully monitored and examined, policy systems learn and adapt accordingly., ${ }^{2,41}$ In the worst-case scenario, mistakes persist and propagate, and their consequences defy public interest. ${ }^{2}$

In some instances, policy can be successful even if decision makers have had little experience in solving the same kind of problem before, e.g., the ozone layer hole (for more details, see Ref 42). In others, decision makers' lack of experience can limit the action they are willing to take. Climate change, for example, was identified by science as a problem before it became a public policy problem. And partly because neither the public nor policy makers could experience many of its negative consequences directly, acting preventively has been at best challenging and at worst virtually impossible. Sarewitz and Pielke ${ }^{43}$ have argued that the early marriage between climate change and science has been critical in defining climate policy. On the one hand, pegging climate change to science gave the environmental movement its first impetus to link many of the problems that they were interested in solving (such as pollution, loss of forests) to something global and urgent. On the other hand, it alienated decision makers because it was a problem outside their experience. ${ }^{43}$ As a scientific problem, climate change has had a hard time galvanizing support among the public. This is in part due to the 'scientific controversy' surrounding its causes and effects that did little to attract and accumulate the necessary political capital to back up unpopular and costly policy to mitigate and prepare for its negative consequences. For decision makers reluctant to commit to concrete policies, the uncertainty and controversy in scientific investigation helps justify their avoidance of difficult decisions, for which their investment in science becomes a replacement.

Yet, the over-reliance on science may also sidestep the moral imperative of doing what is right. The way the climate change problem has been framed provides the perfect opportunity for policy gridlock, while ignoring effective action to decrease vulnerability to climate impacts. ${ }^{43}$ Indeed, the technical 'solution' may crowd out the moral imperative to do what is needed to improve livelihoods, conserve natural resources, and increase the resilience of human 
systems and ecosystems. ${ }^{25,44}$ In northeast Brazil, for example, rather than addressing structural deficits at the heart of vulnerability to drought (e.g., unequal income and land distribution, lack of education, health, and political power), local technocrats and politicians often opted to invest in technical solutions such as cloud seeding to 'produce' rain or SCFs to respond to drought. ${ }^{25}$ They did so despite their high level of uncertainty, because this option was politically and financially less costly.

Institutional constraints also play a critical role in the way policy makers make decisions to use science. ${ }^{30,31,45}$ Despite the fact that decision makers frequently make decisions that include hard-topredict human behavior, ${ }^{3}$ they may have difficulty in extending the same experience to climate change, because they perceive climate change as physical science driven and therefore predictable. Moreover, as mentioned before, scientists have often expressed their faith not only in the usefulness of climate predictions but also in their ability to continuously produce better information. ${ }^{46,47}$ This faith, in turn, might have encouraged decision makers to believe that a waitand-see approach would be reasonable, especially considering powerful opposition from special interests (e.g., oil and coal industry) and the lack of political capital to make tough decisions about climate change under high levels of uncertainty. Paradoxically, what decision makers initially may have liked about climate change as a problem-that it was predictable scientifically-is precisely what now they offer as a reason to delay action. However, while inaction may be convenient, 'the argument, that scientific uncertainty must be resolved before action should be taken, disregards the fact that no amount of data or theory will be able to eliminate all uncertainty regarding future temperature changes' (Ref 2, p. 438). Yet, uncertainty may become a pretext for inaction, a rationale for selfserving selection of scientific opinion, or a license to ignore scientists. ${ }^{2}$ For example, in the 1990 s, industrial interests that became significantly prominent in the global change debate in the years leading to the Kyoto Conference used the uncertainty argument to advocate against 'policy that would hurt the US's economy'. ${ }^{48}$ In the mid-2000s, the Bush administration was able to '[enlist] an outspoken skeptic of global warming' in a fight regarding overseas energy projects (Kintisch 2005:482 cited by Ref 49).

The level of uncertainty of predictions, however, is not a fixed quantity that affects all processes in the same way; different policy decisions can tolerate different levels of uncertainty. For example, surprisingly to many, the decision to protect the ozone layer was achieved relatively quickly and efficiently despite considerable uncertainty and lack of scientific consensus. ${ }^{48}$ As described in the previous section, there are many kinds of uncertainty and they may affect the use of predictions in decision making differently.

Finally, scientists and decision makers have, difficulty communicating not only about the uncertainty of predictions $s^{34,50-52}$ but also about whether and how fast the science behind it would progress to a level decision makers would perceive as usable. ${ }^{52}$ Throughout, climate modelers have persisted in justifying further funding for prediction research on its potential for usability. ${ }^{46,53}$ From the point of view of some natural scientists, we pose that there is an uncertainty fallacy, that is, a belief that the systematic reduction of uncertainty in climate projections is required in order for the projections to be used by decision makers. However, evidence from the SCF literature (see the following section) shows that there are many constraints to the use of SCF in decision making, not all of them related to the level of uncertainty of the forecasts. ${ }^{32,54,55}$ Moreover, there is ample evidence that policy makers and other stakeholders such as farmers often make decisions under high levels of uncertainty. 3,33,56 Figure 1 proposes a framework to think about how uncertainty affects use and what mediating factors influence how perceptions of usefulness change.

The top left graph in Figure 1 is from the IPCCAR4 and shows the projection of the global surface warming in the year 2100 for a number of emission scenarios. It is used to symbolically represent the products of scientific investigation. There are two products. The first product is the knowledge that the Earth will warm. This type of knowledge, which might be viewed as factual, is easily grasped. The second outcome of scientific investigation is the uncertainty associated with that warming projection, which challenges its factual nature. Hence, the presence of uncertainty fuels scientific and political arguments. This is especially true if the uncertainty can be construed as 'large'. In this context, action depends not only on scientific knowledge and the specification of uncertainty but also on the values and political calculations of policy makers tasked with responding to the risks and benefits represented by the warming of the Earth. It also depends on the customization of the knowledge to meet decision-makers' needs, including knowledge representation, communication, and contextualization. For some, the knowledge that the Earth will warm at dangerous levels is compelling enough that they seek to mitigate the warming and plan to adapt to the warming. For others, the uncertainty is large enough that they feel that it is premature to make a decision until more is known. 


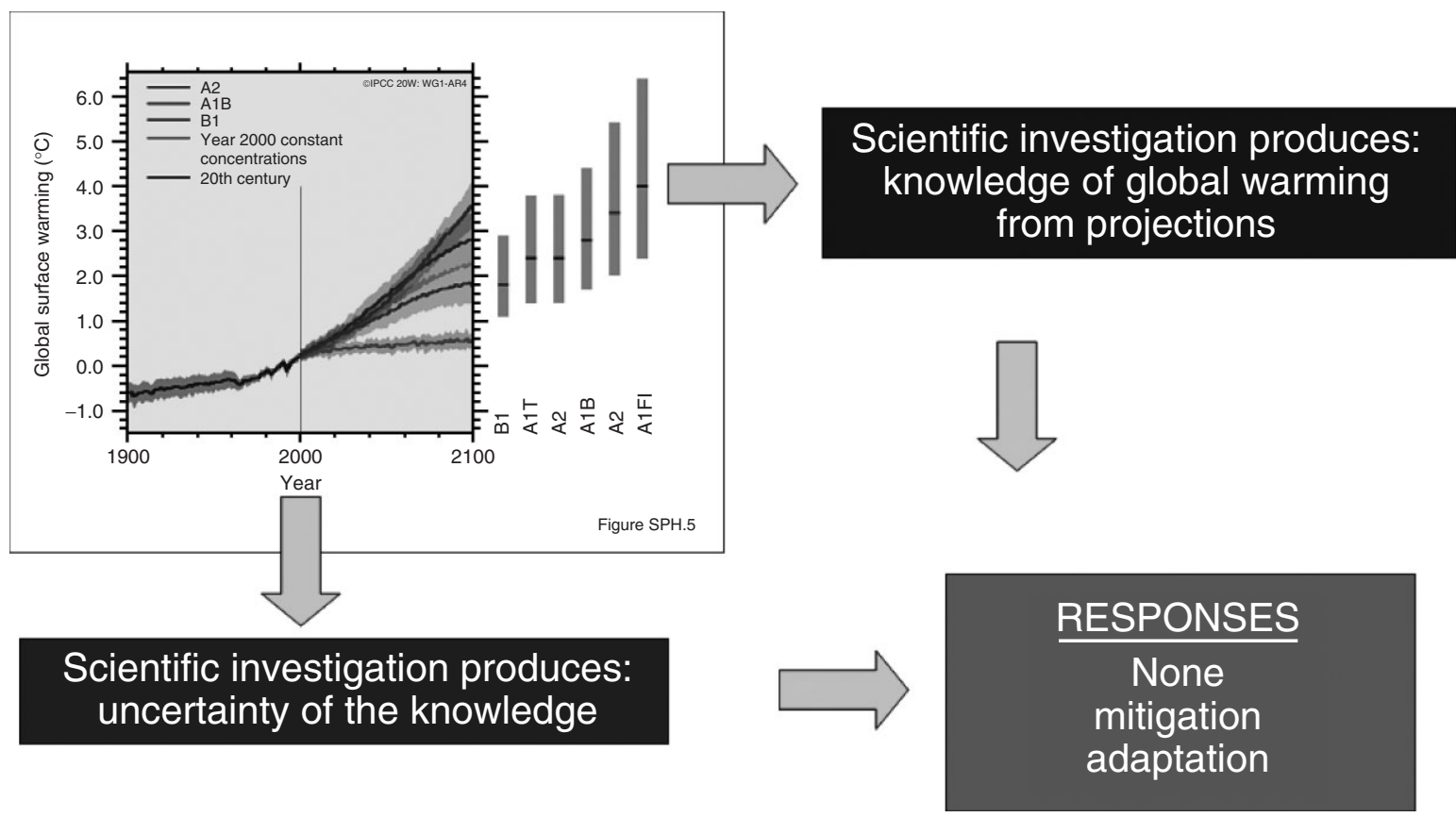

FIG URE 1 | Knowledge and uncertainty of that knowledge are both products of scientific investigation. Knowledge and uncertainty combine with values and political will to influence responses. Uncertainty always exists, and in complex problems, new investigation reveals new sources of uncertainty. Uncertainty reduction is uncommon. Uncertainty can always be used, politically, to fuel selective doubt to disrupt the development of knowledge-based responses.

Still for others, the uncertainty justifies and supports their decision to avoid action they did not want to carry out in the first place. In practice, what these different interpretations mean is that the uncertainty surrounding scientific knowledge can always be used by stakeholders to justify their positions. Thus, the inevitable uncertainty of knowledge created by scientific investigation makes up only a part of the uncertainty of other types of knowledge that inform decision making.

\section{PREDICTION IN PRACTICE: LESSONS FROM SCF APPLICATION}

In principle, seasonal climate forecasts (SCFs) have many applications. For the past 15 years, a rich empirical literature focusing on the use of SCFs in different sectors in different parts of the developed and developing worlds has emerged both in the social and natural sciences. ${ }^{24,32,54,55,57-61}$ Findings from this literature suggest that successful application of SCF tends to follow a systems approach where SCF is contextualized to the decision situation and embedded within an array of other information relevant for risk management. For example, in Australia, users and producers of SCF have created knowledge systems for action in which the forecasts are part of a broader range of knowledge that informs farmers' decision making. ${ }^{23}$ In Arizona, forecast producers have interacted closely with potential users to customize information's formatting, frequency, and focus. ${ }^{29,30}$ By contrast, in other cases, evidence shows that there might be opportunity costs to the application of forecasts, ranging from the crowding out of more sustainable and robust alternatives to actually harming users whose decisions and wellbeing forecasts were meant to improve..$^{25,32,62}$ For example, in Peru, a forecast of El Niño and the prospect of a weak season gave fishing companies incentive to accelerate seasonal layoffs of workers. ${ }^{62}$ In Zimbabwe, forecast of a bad season resulted in reduced credit availability and planted areas. ${ }^{63}$

Seeking to apply the lessons from the SCF application to inform climate-adaptation policy, more recent scholarship similarly argues for integration of predictions within broader decision contexts. These predictions should take into consideration not just the magnitude and dimension of exposure to climate impacts (to which impacts predictions may be more relevant) but also characterize sensitivities related to livelihoods, institutions, politics, cultures, etc. $55,58,59,64$ Particularly in countries and communities where lack of resources critically defines vulnerability, adaptation policy should not be dependent 
on predictions since capacity building ought to be precisely about enabling flexible and robust human, environmental, and physical systems to withstand a wide range of impact. In these contexts, climate hazard such as storms, sea level rise, and warmer temperatures make up only one aspect of vulnerability. In such contexts, integrated assessments and participatory approaches that contextualize the information to the users' multiple stresses and needs make more sense than do 'perfect' forecasts. To jump start policy action, policy makers need 'plausible representations of future climate' that can help them understand where vulnerabilities lie and what to do to decrease these vulnerabilities. ${ }^{44}$ Relative to uncertainty, climate impacts are only one in a cascade of uncertainties that aggregate across physical, social, cultural, and political factors. ${ }^{65}$ And climate predictions themselves can magnify this uncertainty, in that it is impossible to predict the consequences of human behavior that this kind of information might motivate. ${ }^{66}$

Hence, in the context of compounded or irreducible uncertainty, it seems more sensible to search for resilient and robust approaches to decision making that seek to identify strategies that are less sensitive to wide ranges of uncertainties. ${ }^{52,67,68}$ For example, 10 years of experience with climate forecasting application in Africa suggest that incorporating forecasts within broader sustainability approaches are likely to produce better results than isolated attempts to inform action by the use of forecasts alone. ${ }^{63}$ Other strategies may include 'noregrets' or precautionary approaches that allow for future adjustment as the dimension of climate impact and response evolve. They may also include the support of powerful computational resources, which may not decrease uncertainties but rather help to better uncover them so that decision makers 'have better discovery of all issues bearing on the decision'. ${ }^{4,52}$ Most importantly, the application of climate predictions and projections should not crowd out other approaches that are likely to enhance the adaptability of people and systems to climate impact. ${ }^{32}$ As Hulme and Dessai write

Effective and robust adaptation strategies are not significantly limited by the absence of accurate and precise regional climate predictions. They are limited more by a multitude of technological, institutional, cultural, economic and psychological factors that lie beyond the reach of climate models-and always will. The epistemological limits to predicting future climates with accuracy and precision must not be used as a reason to limit adaptation to climate change (Ref 53, p. 979).

We pose Figure 2 as a model for organizing effective use of climate projections in decision making. As in Figure 1, the graph represents the products of scientific investigation and the motivation to respond in the presence of uncertain knowledge. If there is to be effective response in, for example, building adaptive capacity, then it is necessary to reduce the problem at hand to manageable elements. Useful reductions are aligned along a temporal axis as near term and long term. Spatially, issues are distinguished between local and global scales. The third axis is wealth, which serves to represent several aspects that influence the problem, ranging from the ability to build adaptive capacity to issues of environmental justice. When problems are reduced along these axes, interfaces between issues can be isolated, and the likelihood is increased that tensions between competing issues can be rationalized. Problems at one set of scales can then be viewed to inform problems at another set of scales, rather than all problems being conflated. This approach to problem solving is most likely to be successful when scientists and stakeholders interact and gain intuitive understanding of the role of uncertainties in their different communities.

As the reality of climate change as a problem becomes universally salient, the need for climaterelated policy has risen in many countries' public policy agendas. What we do not know about both physical and social determinants of vulnerability and adaptive capacity is large. However, what we do know is enough to jump start action that will allow for future adjustment and learning, especially if decision makers and the public weigh the nature and character of uncertainty against the likely consequences of inaction.

\section{CONCLUSION}

This article has reviewed both the sources of uncertainty in the projections of climate change and how uncertainty shapes decision making. In particular, we have explored the gap between the potential usefulness of climate projections and how they are used in practice.

Uncertainty is an inherent element of scientific investigation of climate. In many cases, uncertainties will get even larger, as scientific investigation will continue to reveal new sources of uncertainty in models of a system as complex as that of the Earth's climate. Systematic reduction of uncertainty by continued scientific investigation is not, a priori, expected. The 


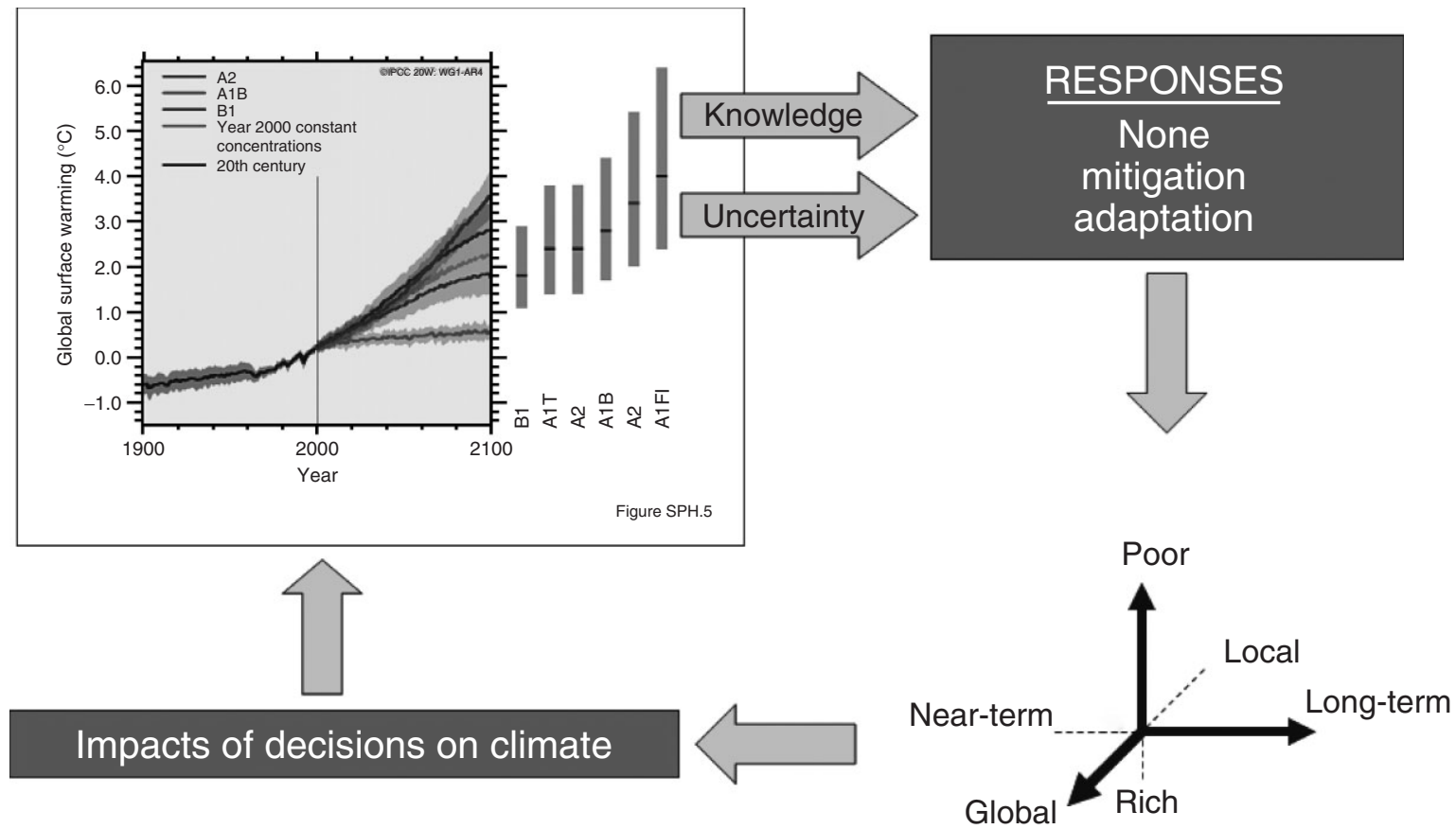

FI G URE 2 | Climate-change problem solving by reduction of problems along axes of time, spatial scale, and wealth. This reduction enhances communication between scientists and stakeholders and improves the likelihood of successful problem solving.

emergence of ensemble forecasts as a new technology suggests that scientists are seeking to purposefully manage uncertainties in the forecast system to provide improved, presumably more usable, forecasts.

Calls for the reduction of uncertainty may be understandable from both scientists and decision makers. Some scientists and decision makers such as water and coastal managers' statements that better predictions are necessary are sensible because it is reasonable to expect that improved predictions will lead to improved usability. Similarly, for those making difficult decisions with high stakes, it is reasonable to hope that support from science would streamline the policy process and clarify decision options. However, a great deal of what we know of both the production of scientific knowledge and its application in decision making suggests that neither process is entirely rational or straightforward. In addition, progress in the science of climate prediction has been slower than both scientists and decision makers expected and hoped. By ignoring the complexities of each other's tasks, both scientists and policy makers may be denying society better solutions to the climate change problem.

Part of the disconnection between what decision makers know they need and what scientists think is useful may be explained by the way climate change first became a public policy problem. Because climate change originally was perceived as a problem by scientists rather than experienced by society, support for climate policy has been relatively slow to build. The gap between how scientists and decision makers perceive usefulness and usability also contributed to some decision makers being able to use uncertainty as a justification to inaction. The high-stakes character of climate policy and the financial and political costs associated with effective response amplify this gap and further invite inaction.

Regarding scientific investigation, we suggest that there is an uncertainty fallacy, that is, a belief that systematic reduction of uncertainty will lead to the development of policy and the rationalization of decision making. Aside from ignoring the intrinsic uncertain character of climate science and the overall complexity of uncertainty in scientific investigation, this notion does not recognize how scientific uncertainty affects the decision-making process. Partly because of uncertainty, in the absence of clear and present danger, those who so wish can sustain their arguments of doubt to justify inaction both for mitigation and adaptation.

Empirical evidence from the literature on use of SCFs indicates that beyond uncertainty, many other factors influence the usability of climate projections. These include other stressors that shape the decision-making environment of potential users (e.g., lack of alternative technologies to respond to climate projections, lack of resources) as well as issues of communication, availability, trust, and legitimacy 
of knowledge. To increase the usability of climate projections, there needs to be collaboration and interaction between scientists and decision makers, especially concerning the adoption of a knowledge systems approach that takes into consideration not only the decision environment of potential users but also different ways to manage uncertainty to better meet their needs.

\section{NOTE}

${ }^{a}$ While the term climate projections more closely reflects current attempts to predict future impacts of climate change, hereafter we use the more commonly utilized climate predictions recognizing that the discrepancy between the two terms has itself political and policy implications.

\section{ACKNOWLEDGEMENTS}

The authors thank Linda Mearns and Owen Johns for their careful reading and review of the article. They thank Mary Ann Rood for her thorough edit and the three anonymous reviewers and Myanna Lahsen for their valuable suggestions to the original article.

\section{REFERENCES}

1. IPCC. Climate Change 2007: The Physical Science Basis. Summary for Policymakers. Contribution of Working Group I to the Fourth Assessment Report of the Intergovernmental Panel on Climate Change. Geneva, Switzerland: Intergovernmental Panel on Climate Change; 2007, 18.

2. Ascher W. Scientific information and uncertainty: challenges for the use of science in policymaking. Sci Eng Ethics 2004, 10:437-455.

3. CCSP. Impacts of climate change and variability on transportation systems and infrastructure: Gulf Coast study, phase I. In: Savonis MJ, Burkett VR, Potter JR, eds. A Report by the US Climate Change Science Program and the Subcommittee on Global Change Research. Washington, DC: Department of Transportation; 2008, 445.

4. Lempert RJ, Popper SW. High-performance government in an uncertain world. Presented at Conference of the Pardee-RAND-Graduate-School on HighPerformance Government, Santa Monica, CA, March 2004.

5. NRC. Evaluating Progress of the U.S. Climate Change Science Program: Methods and Preliminary Results. Washington, DC: National Research Council of the National Academies; 2007.

6. Weart SR. The Discovery of Global Warming. Cambridge, MA: Harvard University Press; 2008.

7. Arrhenius S. On the influence of carbonic acid in the air upon the temperature of the ground. Philos Mag 1896, 41:237-276.

8. Callendar GS. The artificial production of carbon dioxide and its influence on climate. Quart J R Meteor Soc 1938, 64:223-240.

9. Budyko M. The future climate. EOS Trans Am Geophys Union 1972, 53:868-874.
10. Manabe S. Climate and ocean circulation. I. Atmospheric circulation and hydrology of Earth's surface. Mon Weather Rev 1969, 97:739.

11. Farber DA. Climate Models: A Users Guide. Berkeley: University of California; 2007.

12. Lahsen M. Seductive simulations? Uncertainty distribution around climate models. Soc Stud Sci 2005, 35:895-922.

13. Palmer TN, Doblas-Reyes FJ, Hagedorn R, Weisheimer A. Probabilistic prediction of climate using multi-model ensembles: from basics to applications. Philos Trans R Soc B Biol Sci 2005, 360:1991-1998.

14. Giorgi F. Climate change prediction. Clim Change 2005, 73:239-265.

15. Palmer TN. Predicting uncertainty in forecasts of weather and climate. Rep Prog Phys 2000, 63:71-116.

16. Palmer TN, Doublas-Reyes FJ, Weisheimer A, Rodwell MJ. Toward seamless prediction: calibration of climate change projection using seasonal forecasts. Bull Am Meteor Soc 2008, 89:459-470.

17. Shackley S, Wynne B. Representing uncertainty in global climate change science and policy: boundaryordering devices and authority. Sci Tech Human Values 1996, 21:275-303.

18. Kandlikar M, Risbey J, Dessai S. Representing and communicating deep uncertainty in climate-change assessments. Comptes Rendus Geosci 2005, 337:443-455.

19. USGCRP. In: Karl TR, Melillo JM, Peterson TC, eds. Global Climate Change Impacts in the United States. New York: Cambridge University Press; 2009, 192 pp. Available at: http://downloads.globalchange. gov/usimpacts/pdfs/climate-impacts-report.pdf.

20. Pollack HN. Uncertain Climate ... Uncertain World. Cambridge, UK: Cambridge University Press; 2003.

21. Kopp RE, Simons FJ, Mitrovica JX, Maloof AC, Oppenheimer M. Probabilistic assessment of sea level 
during the last interglacial stage. Nature 2009, 462:863-867.

22. Hempel L. Environmental Governance: The Global Challenge. Washington, DC: Island Press; 1996.

23. Hartmann HC, Pagano TC, Sorooshian S, Bales R. Confidence builders: evaluating seasonal climate forecasts from user perspectives. Bull Am Meteorol Soc 2002, 8:683-698.

24. Pagano TC, Hartmann HC, Sorooshian S. Factors affecting seasonal forecast use in Arizona water management: a case study of the 1997-98 El Nino. Clim Res 2002, 21:259-269.

25. Lemos MC. A tale of two policies: the politics of seasonal climate forecast use in Ceará, Brazil. Policy Sci 2003, 32:101-123.

26. McNie EC. Reconciling the supply of scientific information with user demands: an analysis of the problem and review of the literature. Environ Sci Policy 2007, 10:17-38.

27. Lemos MC, Morehouse B. The co-production of science and policy in integrated climate assessments. Glob Environ Change 2005, 15:57-68.

28. Ingram KT, Roncoli C, Kirshen PH. Opportunities and constraints for farmers of west Africa to use seasonal precipitation forecasts with Burkina Faso as a case study. Agric Syst 2002, 74:331-349.

29. Cash D, Buizer J. Knowledge-action Systems for Seasonal to Interannual Climate Forecasting: Summary of a Workshop. Roundtable on Science and Technology for Sustainability, Policy and Global Affairs. Washington, DC: National Research Council of the National Academies; 2005.

30. Lemos MC. What influences innovation adoption by water managers? Climate information use in Brazil and the US. J Am Water Resour Assoc 2008, 44:1388-1396.

31. Rayner S, Lach D, Ingram H. Weather forecasts are for wimps: why water resource managers do not use climate forecasts. Clim Change 2005, 69:197-227.

32. Lemos MC, Dilling L. Equity in forecasting climate: can science save the world's poor? Sci Pub Policy 2007, 34:109-116.

33. Ingram H, Feldman DL, Jacobs KL, Mantua N, Lemos MC, Morehouse B, Waple AM, Beller-Simms N. Looking toward the future. In: Beller-Simms N, Ingram H, Feldman D, Mantua N, Jacobs KL, Waple AM, eds. Decision-support Experiments and Evaluations Using Seasonal-to-interannual Forecasts and Observational Data: A Focus on Water Resources A Report by the U.S. Climate Change Science Program and the Subcommittee on Global Change Research. Asheville, NC: NOAA's National Climatic Data Center; 2008, 141-154.

34. Dilling L, Moser S. Creating a Climate for Change: Communicating Climate Change and Facilitating Social Change. Cambridge, UK: Cambridge University Press; 2007.

35. Hulme M, Dessai S. Negotiating future climates for public policy: a critical assessment of the development of climate scenarios for the UK. Environ Sci Policy 2008, 11:54-70.

36. Christine K. Integrating Science and Policy: Climate Change Assessments and Water Resources Management. Unpublished PhD Dissertation, School of Natural Resources and Environment, University of Michigan; 2010.

37. Agrawala S, Broad K, Guston DH. Integrating climate forecasts and societal decision making: challenges to an emergent boundary organization. Sci Technol Human Values 2001, 26:454-477.

38. Weiss $\mathrm{CH}$. Improving the linkage between social research and public policy. In: Lynn LE, ed. Knowledge and Policy: The Uncertain Connection. Washington, DC: National Academy of Sciences; 1978.

39. NRC. Informing Decisions in a Changing Climate-Panel on Strategies and Methods for Climate-related Decision Support. Washington, DC: National Research Council of the National Academies; 2009.

40. Lemos MC, Finan T, Fox R, Nelson D, Tucker J. The use of seasonal climate forecasting in policymaking: lessons from Northeast Brazil. Clim Change 2002, 55:479-507.

41. Pressman JL, Wildavsky AB. Implementation: How Great Expectations in Washington Are Dashed in Oakland: Or, Why It's Amazing that Federal Programs Work At All, This Being a Saga of the Economic Development Administration as Told by Two Sympathetic Observers Who Seek to Build Morals on a Foundation Of Ruined Hopes. Berkeley: University of California Press; 1973.

42. Skjaerseth JB. The 'successful' ozone-layer negotiations are there any lessons to be learned? Glob Environ Change 1992, 4:292-300.

43. Sarewitz D, Pielke R Jr. Breaking the global-warming gridlock. Atl Mon 2000, 286:54-64.

44. Hulme M. Why We Disagree About Climate Change: Understanding Controversy, Inaction and Opportunity. Cambridge, UK: Cambridge University Press; 2009.

45. van Kerkhoff L, Lebel L. Linking knowledge and action for sustainable development. Ann Rev Environ Resour 2006, 31:445-477.

46. Bedritsky AI. From prediction to action: meteorology and the war on climate change. Harvard Int Rev 2008, Summer:52-56.

47. Shukla J, Hagedorn R, Hoskins B, Kinter J, Marotzke J, Miller M, Palmer TN, Slingo J. Revolution in climate prediction is both necessary and possible: a declaration at the world modelling summit for climate prediction. Bull Am Meteorol Soc 2009, 90:175-178.

48. Grundmann R. Ozone and climate-scientific consensus and leadership. Sci Technol Hum Values 2006, 31:73-101.

49. Freudenburg WR, Gramling R, Davidson DJ. Scientific certainty argumentation methods (SCAMs): science and the politics of doubt. Sociol Inq 2008, 78:2-38. 
50. CCSP. In: Beller-Simms N, Ingram H, Feldman D, Mantua N, Jacobs KL, Waple AM, eds. Decisionsupport Experiments and Evaluations using Seasonalto-interannual Forecasts and Observational Data: A Focus on Water Resources. A Report by the U.S. Climate Change Science Program and the Subcommittee on Global Change Research. Asheville, NC: NOAA's National Climatic Data Center; 2008, 192.

51. Schenk NJ, Lensink SM. Communicating uncertainty in the IPCC's greenhouse gas emissions scenarios. Clim Change 2007, 82:293-308.

52. CCSP. In: Morgan G, Dowlatabadi H, Henrion M, Keith D, Lempert R, McBrid S, Small M, Wilbanks T, eds. Best Practice Approaches for Characterizing, Communicating, and Incorporating Scientific Uncertainty in Decision Making. Washington, DC: National Oceanic and Atmospheric Administration; 2009.

53. Hulme M, Dessai S. Ventures should not overstate their aims just to secure funding. Nature 2008, 453:979.

54. Vogel C, O’Brien K. Who can eat information? Examining the effectiveness of seasonal climate forecasts and regional climate-risk management strategies. Clim Res 2006, 33:111-122.

55. Meinke H, Nelson R, Kokic P, Stone R, Selvaraju R, Baethgen W. Actionable climate knowledge: from analysis to synthesis. Clim Res 2008, 33:101-110.

56. Broad K, Pfaff A, Taddei R, Sankarasubramanian A, Lall U, de Souza FD. Climate, stream flow prediction and water management in northeast Brazil: societal trends and forecast value. Clim Change 2007, 84:217-239.

57. Harrison M. The development of seasonal and interannual climate forecasting. Clim Change 2005, 70:201-220.

58. Johnston PA, Archer ERM, Vogel CH, Bezuidenhout CN, Tennant WJ, Kuschke R. Review of seasonal forecasting in South Africa: producer to end-user. Clim Res 2004, 28:67-82.

59. Roncoli C, Jost C, Kirshen P, Sanon M, Ingram KT, Woodin M, Some L, Ouattara F, Sanfo BJ, Sia C, Yaka P, Hoogenboom G. From accessing to assessing forecasts: an end-to-end study of participatory climate forecast dissemination in Burkina Faso (West Africa). Clim Change 2009, 92:433-460.

60. Zebiak S, Cane MA. A model El Niño/Southern oscillation. Mon Weather Rev 1987, 115:2262-2278.

61. Gilles JL, Valdivia C. Local forecast communication in the Altiplano. Bull Am Meteorol Soc 2009, 90:85-91.

62. Broad K, Pfaff ASP, Glantz MH. Effective and equitable dissemination of seasonal-to-interannual climate forecasts: policy implications from the Peruvian fishery during El Niño 1997-98. Clim Change 2002, 54:415-438.

63. Patt AG, Ogallo L, Hellmuth M. Sustainability-learning from 10 years of climate outlook forums in Africa. Science 2007, 318:49-50.

64. Klopper E, Vogel CH, Landman WA. Seasonal climate forecasts-potential agricultural-risk management tools? Clim Change 2006, 76:73-90.

65. Adger WN, Vincent K. Uncertainty in adaptive capacity. C R Geoscience 2005, 337:399-410.

66. Dessai S, Hulme M. Does climate adaptation policy need probabilities? Clim Policy 2004, 4:107-128.

67. Lempert R, Nakicenovic N, Sarewitz D, Schlesinger M. Characterizing climate-change uncertainties for decision-makers-an editorial essay. Clim Change 2004, 65:1-9.

68. Lempert RJ, Collins MT. Managing the risk of uncertain threshold responses: comparison of robust, optimum, and precautionary approaches. Risk Anal 2007, 27:1009-1026.

\section{FURTHER READING}

Betz G. Probabilities in climate policy advice: a critical comment. Clim Change 2007, 85:1-9.

Dessai S, Hulme M. Assessing the robustness of adaptation decisions to climate change uncertainties: a case study on water resources management in the East of England. Glob Environ Change (Human Policy Dimens) 2007, 17:59-72.

Hulme M. Why We Disagree About Climate Change: Understanding Controversy, Inaction and Opportunity. Cambridge, UK: Cambridge University Press; 2009.

Johnston PA, Archer ERM, Vogel CH, Bezuidenhout CN, Tennant WJ, Kuschke R. Review of seasonal forecasting in South Africa: producer to end-user. Clim Research 2004, 28:67-82.

Lempert R, Nakicenovic N, Sarewitz D, Schlesinger M. Characterizing climate-change uncertainties for decisionmakers-an editorial essay. Clim Change 2004, 65:1-9.

Nelson DR. The Public and Private Sides of Persistent Vulnerability to Drought: An Applied Model for Public Planning in Ceará, Brazil. Unpublished PhD Dissertation, Department of Anthropology, University of Arizona, Tucson, AZ; 2005.

Pielke R Jr. The Honest Broker: Making Sense of Science in Policy and Politics. Cambridge, UK: Cambridge University Press; 2008.

Vogel C, Moser SC, Kasperson RE, Dabelko GD. Linking vulnerability, adaptation, and resilience science to practice: pathways, players, and partnerships. Glob Environ Change (Human Policy Dimens) 2007, 17:349-364. 